\title{
Using TEM Operando Methods to Understand Energy Storage
}

\author{
C. Barry Carter ${ }^{1,2,3}$, Matthew T. Janish ${ }^{1}$, Katherine L. Jungjohann ${ }^{2}$ and Grant Norton ${ }^{4}$ \\ ${ }^{1 .}$ Dept of Materials Science \& Engineering, U. of Connecticut, 97 North Eagleville Rd, Storrs, CT 06269 \\ 2. Center for Integrated Nanotechnologies, Sandia National Laboratories, Albuquerque, NM 87185 \\ ${ }^{3 .}$ Dept of Chemical \& Biomolecular Engineering, U. of Connecticut, 191 Auditorium Rd, Storrs, CT 06269 \\ 4. The Honors College, Washington State U, Pullman, WA 99164
}

The structure and electrochemistry of battery technologies is well established but is inadequate for anticipated future needs (e.g., $[1,2])$. One aspect that has not been examined thoroughly is exactly how the materials change during cycling between charging and discharging modes. Most studies of these processes rely on electrochemical measurements and indirect assumptions of the processes that are actually involved. The structural changes that occur have been assumed to make certain systems unusable but if the dimensions of the device are changed or if the morphology of the materials involved is reduced, these materials may become of interest, especially if combined with other candidate materials, e.g., in $\mathrm{SnO}_{2} / \mathrm{Sn}$ or $\mathrm{Sn} / \mathrm{C}$ composites.

The use of operando techniques in the transmission electron microscope (TEM) allow, in principle, changes to be monitored as a process proceeds and the structure and chemistry is characterized. The systems that have been most extensively studied using this approach are primarily nanowires and thin sheets that may have application to the improvement of lithium-ion batteries (LIBs); examples include $\mathrm{Si}$ [3-6], Ge [7], $\mathrm{SnO}_{2}$ [8] and $\mathrm{Sn}$ [9] as nanowires, $\mathrm{MoS}_{2}$ [10] as thin films, and $\mathrm{Ge} / \mathrm{Si}$ [11], $\mathrm{Sn} / \mathrm{SnO}_{2}$ [12], or $\mathrm{SnO}_{2} / \mathrm{C}[13]$ as composite materials or just crystalline/amorphous core shell composites of the same material [14].

In the studies described in this paper, a Nanofactory STM holder has been used to carry out the initial lithiation experiment in an FEI Tecnai F30 TEM operated at $300 \mathrm{kV}$ [8]. Other manufacturers now offer similar holders, but the restriction to open half-cells that rely on solid or ionic liquid electrolytes is beginning to be appreciated as a real limitation. The initial experiments are therefore being extended using the CINT Discovery platform, which allows the observation of electrochemical processes in a liquid (e.g., commercial electrolyte) environment and can be optimized for different holders and different microscopes.

Examples of results obtained from such studies are shown in Figures 1 and 2 for the in-situ lithiation of $\mathrm{MoS}_{2}$ : Figure 1 shows the basal planes edge on, while in Figure 2 these planes are in plan view. The talk will also consider how in-situ TEM can reveal the advantages of using Sn nanowires rather than Si as alternatives to $\mathrm{C}[15]$.

References:

[1] Huggins RA (2009) Advanced Batteries: Materials Science Aspects. Springer US,

[2] Goodenough JB, Kim YU, Chem Mater 22 (2010), p. 587.

[3] Zhang Q et al, Nano letters 10 (2010), p. 3243.

[4] Zhao K et al, Nano letters 11 (2011), p. 2962.

[5] Chan CK et al, Nature Nanotechnol 3 (2008), p. 31.

[6] Liu XH et al, Nano letters 11 (2011), p. 2251.

[7] Liu XH et al, Nano letters 11 (2011), p. 3991.

[8] Huang JY et al, Science 330 (2010), p. 1515. 
[9] Janish MT et al, Journal of Materials Science 51 (2015), p. 589.

[10] Janish MT, Carter CB Scripta Materialia 107 (2015), p. 22.

[11] Yu YJ et al, Acs Applied Materials \& Interfaces 6 (2014), p. 5884.

[12] Hu YM et al, Electrochimica Acta 186 (2015), p. 271.

[13] Wang X et al, Adv Functional Mater 22 (2012), p. 2682.

[14] Cui L-F et al, Nano letters 9 (2009), p. 491.

[15] MTJ would like to acknowledge GAANN Fellowship from the Department of Education. This work was performed at Sandia National Laboratory at the Center for Integrated Nanotechnologies, a DOE-BES supported national user facility, and in the Materials Characterization Department. Sandia is a multiprogram laboratory operated by Sandia Corporation, a Lockheed Martin Company, for the US Department of Energy under contract DEAC04-94AL85000.

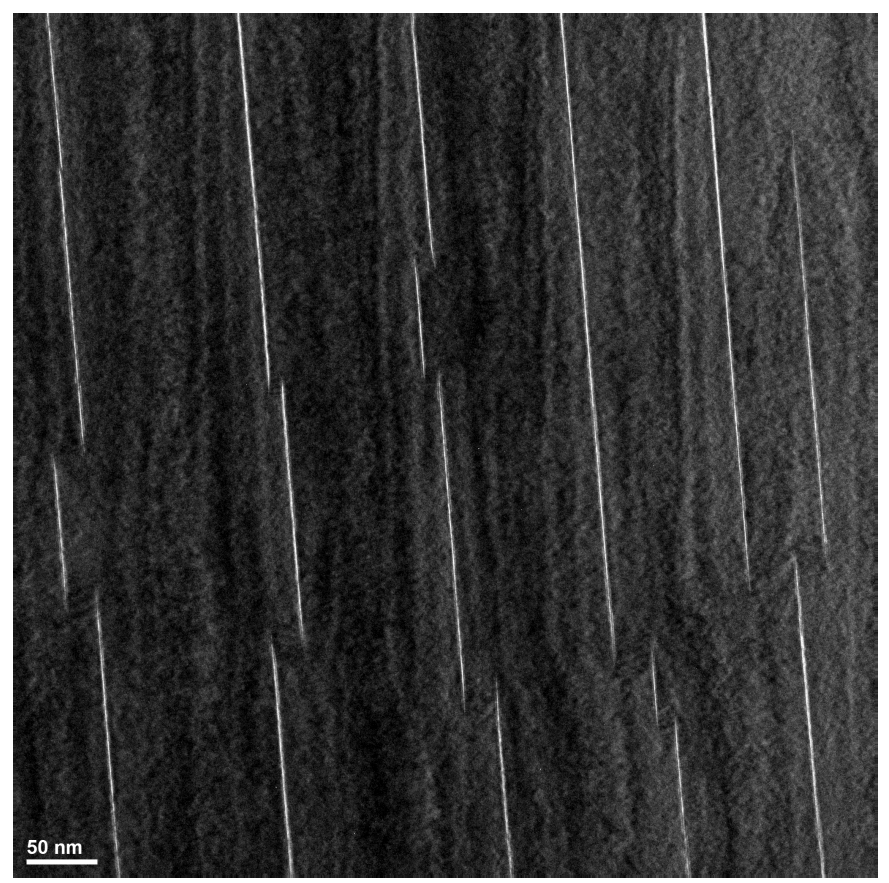

Above: Figure 1 planar defects in a FIB sample of $\mathrm{MoS}_{2}$ following in-situ lithiation [10]. The planar defects are flat but can step across several basal planes.
Below: Figure 2: Plan-view sample of $\mathrm{MoS}_{2}$ following in-situ lithiation. The very dark bands are thought to be mainly Mo with the lighter regions being different Mo-Li sulphides. XEDS of this materials system is complicated by the $\mathrm{Mo} / \mathrm{S}$ pathological overlap.

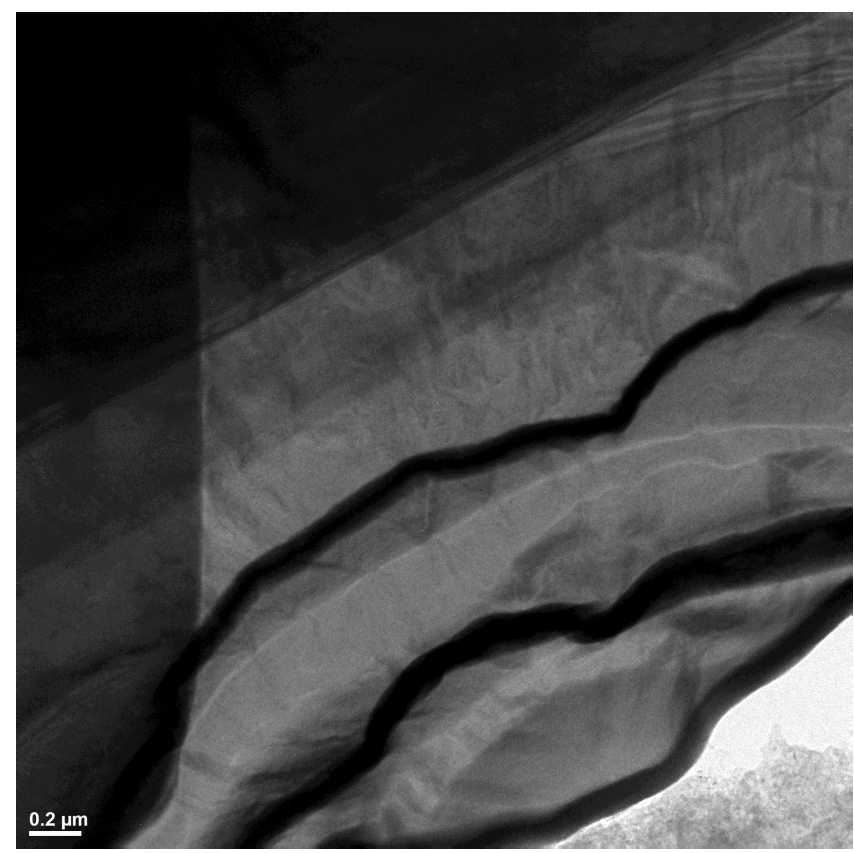

